\title{
Exploring Family Caregivers' Subjective Experience of Positive Aspects in Home-Based Elder Caregiving: From Korean Family Caregivers' Experience
}

\author{
Jung Hee Lee ${ }^{1}$ \\ ${ }^{1}$ Fort Hays State University, United States \\ Correspondence: Jung Hee Lee, Fort Hays State University, United States.
}

Received: May 26, 2020

Accepted: June 24, 2020

Available online: June 29, 2020

doi:10.11114/ijsss.v8i4.4876

URL: https://doi.org/10.11114/ijsss.v8i4.4876

\begin{abstract}
Recently research has identified positive dimensions of the caregiving experience. However, there is still a dearth of research into positive aspects of home-based family caregiving for older adults in various cultural contexts. This exploratory study seeks to expand our knowledge in this area by exploring the positive experience of Korean family caregivers who cared for older adults with frailty at home and how they can transform their caregiving experience into positive one despite of many challenges. Eighteen family caregivers were explored through semi-structured in-depth interviews. Participants reported several positive aspects from their home-based elder caregiving experience. The positive aspects were categorized into three groups; relational aspects, personal aspects, and spiritual aspects. Findings indicate that Koran family caregivers of older adults in this study perceive that caregiving experience is challenging but also offers an opportunity for gains.
\end{abstract}

Keywords: family caregiving, positive aspects of caregiving, elder caregiving, Korean family caregiver

\section{Introduction}

\subsection{Aging Population and Family Caregiving}

The family has been the primary helping source for older family members with frailty throughout human history. In the times of the aging of the baby boomer population, families are still the most valuable unpaid helpers who provide care to frail older adults. The majority of care for the elderly is provided by family members, friends and/or neighbors. In the U.S, for example, informal care was the only care received by $78 \%$ of adults with long-term care needs (Thompson, 2004). Of interest, in South Korea (hereafter "Korea"), the population age 65 or older is growing rapidly. In fact, Korea is one of the fast-aging societies in the world. According to Korea National Statistical Office (2019), the aging rate of Korea passed 14\% of total population (aged society) as of 2017, and it is expected to increase to $20 \%$ in 2025 (supter-aged society) and $43.9 \%$ within next 40 years to be the most aged country in the world. In accordance, the aged dependency ratio, defined as the number of persons aged 65 or older divided by the number of persons aged 15-64, is projected to increase from $15.4 \%$ in 2010 to $100.4 \%$ in 2065 . This implies that younger generation will have to assume a greater responsibility for caring for their older parents in near future.

\subsection{Elder Family Caregiving Burden}

Providing care to older family members with frailty can be meaningful and rewarding for families, but it does not mean that we can disregard the substantial burdens that caregiving responsibilities often create for family caregivers. Family caregivers experience considerable physical, psychological, emotional, social, and financial difficulties, which are often collectively referred to as the caregiver burden (Etters, Goodall, \& Harrison, 2008; Pinquart \& Sörensen, 2007; Schulz et al., 2004). Research studies in Korea also have reported that Korean family caregivers of older adults experienced several similar difficulties; indicating physical problems including headache, chronic fatigue (Lee, Lim, Kim, Cho., \& Ko, 2011), psychological problems including depression, anxiety, and strain (Lee, Seo, \& Ahn, 2003), relational conflicts among family members (Song \& Choe, 2007), and financial difficulties (Song \& Choe, 2007). Thus, family caregivers of older adults are exposed to high risk to experience serious health effects of family caregiving throughout the psychological, physical, and social areas of personal lives. As a result, the interventions grounded in that research have focused on reducing negative outcomes rather than having strengths-based focus, which might increase the 
likelihood of positive outcomes.

\subsection{Strengths Perspective on Family Caregiving for Elders}

Compared with the well-documented negative outcomes of family caregiving, the benefits and possible positive impacts of providing care have received less attention (Berg-Weger, Rubio, \& Tebb, 2001; Kramer, 1997). Despite the pervasive focus in the research literature on the detrimental consequences of family caregiving, many caregivers have something positive to say about their experiences (Kramer, 1997). There is increasing evidence to suggest that family caregivers gain benefits or positive outcomes from the caregiving experience (Hilgeman, Allen, DeCoster, \& Burgio, 2007; Netto, Jenny, \& Philip, 2009; Rapp \& Chao, 2000; Roff et al., 2004). Recent research has identified positive dimensions of the caregiving experience (e.g., Hodge \& Sun, 2012; Robertson, Zarit, Duncan, Rovine, \& Femia, 2007). In specific, Hunt (2003) identified and defined five different positive conceptualizations of caregiving as follows: (1) caregiver satisfaction - the result of caregiving experiences that give life a positive flavor; (2) uplifts of caregiving - events that make one feel good, joyful, or glad, or satisfied; (3) caregiver esteem - the confidence or satisfaction caregivers feel as a direct result of caregiving; (4) gain in the caregiving experience - any positive return to the caregiver as a result of the caregiving experience; and (5) finding or making meaning - assessing positive aspects of and ways to find higher levels of meaning through caregiving (pp. 29 30).

The social work strengths perspective provides a holistic view of caregiving that considers the positive as well as negative influences among family caregivers of older adults with frailty. Embedded within the strengths perspective is the belief that people are capable of growth and change, particularly when empowered to gain insight into their own assets, strengths, and resources (Saleebey, 1996, 2013). Further, from the strengths perspective, the identity of family caregivers of older adults can be redefined not as people who suffer from everyday caregiving burdens and stresses but as collaborators and facilitators who can help care recipients achieve their highest potential despite the difficult circumstances in later life.

As pointed out, addressing the positive aspects of caregiving does not necessarily lead to a disregard for the serious nature of negative outcomes associated with elder caregiving. From the strengths perspective, however, it is important to acknowledge that caregiving can provide enhancement and enrichment not only to the caregiver's own life but also to the care recipient's life despite the negative outcomes. Within the literature related to caregiver gain, the terms caregiver uplifts, satisfaction, gratifications, finding meaning through caregiving, and benefits have been used in reference to the positive attributes derived from caregiving (Rapp \& Chao, 2000). Those positive experiences have been shown to be important for coping and resilience (Folkman, 1997). In particular, those positive aspects of caregiving experience are important, because they are engaged in a meaningful role that really makes a difference in the life of the elderly care recipients (Toseland, Smith, \& McCallion, 2001).

This study seeks to expand our understanding in this area by exploring the positive experience of home-based Korean family caregivers of older adults with frailty. The cultural context affects the way individuals perceive and express caregiver burden like feelings of distress or depression (Dilworth-Anderson and et al., 2005). Once we can better understand the family caregiver's caregiving experience, we can develop interventions to help family caregivers transform their caregiving experience in positive ways.

\section{Method}

This research is exploratory in nature, using qualitative methods to obtain narratives from Korean family caregivers regarding their experiences and perspectives of caregiving. Through in-depth interviews with 18 family caregivers of frail older adults, this study seeks to develop a deeper understanding of Korean family caregivers' perception on their caregiving experiences.

\subsection{Data Sources}

The primary source of data for this study is interviews with 18 Korean family caregivers who care for frail older adults living in a home setting. The caregivers were interviewed individually. Follow-up interviews were also conducted with each caregiver. The transcriptions of the interviews were supplemented by other data sources such as field notes, reflexive journal, and methodological memos.

\subsection{Sampling}

Purposive sampling was used in the selection of the subjects in order to obtain a broad range of perspectives concerning the role of spirituality in relation to caregiving. This purposive sampling method involves the researcher intentionally selecting participants who are identified as being able to provide the most significant or useful information (Meriam, 1998). The selection criteria to participate in this study were: (a) currently providing care for a minimum of 10 hours per week as a primary caregiver of a family member of age 65 or older, (b) the care recipient with frailty must live in a home setting and is not institutionalized, (c) the caregiver must assist the frail elder with at least one of the ADLs and/or 
IADLs, while living together at the same house, (d) both the caregiver and the family member are a Korean living in Korea, (e) the caregiver must have provided care to the same care recipient at least for 1 year, and (f) the caregiver is considered to identify with a religion or to be interested in spirituality.

\subsection{Data Collection}

The data used in this study were gathered face-to-face through 17 semi-structured interviews with 18 participants. The main interview questions were provided for the participants in advance to facilitate the interview process. The face-to-face, in-depth interviews with 18 family caregivers were semi-structured and open-ended. The interviews were done at the participants' home, in their offices, at their friend's house near their home, at the church they attended, or at a café. All the interviews were audio recorded after obtaining participants' permission. The interviews took approximately one to one and a half hour. The interviews were conducted in the Korean language, because all the participants identified Korean as their first language. The interviews were also transcribed verbatim in the Korean language and later translated into English. Follow-up interviews were conducted after the preliminary analytic reading of the first interview transcriptions for the purpose of member checking. Sixteen out of 18 caregivers who participated in the first primary interview also participated in a second interview. . The follow-up interviews were also recorded by using voice recorders after obtaining participants' verbal permission. The follow-up interviews were also transcribed verbatim in the Korean language and analyzed same as initial interviews.

\subsection{Data Analysis}

The transcripts from interviews with 18 Korean family caregivers were the primary sources of data analysis. As soon as the interviews were transcribed, the researcher began to read and reflect and identify potential key themes in the interview data and filed notes. The analysis involved reading and re-reading all of the materials so that they could be categorized and coded for themes. Because of the great volumes of text data in qualitative inquiry, the funneling of information into categories and codes is necessary when trying to make sense of the collected information. The constant comparative method of qualitative data analysis as described by Lincoln and Guba (1985) was employed to analyze data sources. Through constant comparison and contrast between cases and within cases, the tentative findings were examined again. The data was analyzed using ATLAS.ti, which is a computer software for data analysis and management.

\section{Results}

\subsection{Sample Demographics}

The sample is predominantly female (17 female; 1 male) and care recipient's adult children (10 daughter-in-laws; 6 daughters; 1 son; 1 wife). The age range of all participants is between $38 \sim 65$ years old, while care recipients' age ranged from 65 to 102. The participants were providing care to care recipients from 3 to 32 years.

Table 1. Demographic Characteristics of Participants

\begin{tabular}{|c|c|c|c|c|c|c|}
\hline \multirow{2}{*}{ No } & \multirow{2}{*}{$\begin{array}{l}\text { Participant } \\
\text { (Caregiver) } \\
\text { Pseudonym }^{1}\end{array}$} & \multirow{2}{*}{ Age } & \multirow{2}{*}{ Gender } & \multirow{2}{*}{$\begin{array}{c}\text { Relation } \\
\text { to Care Recipient }\end{array}$} & \multicolumn{2}{|c|}{ Care Recipient } \\
\hline & & & & & Gender & Age \\
\hline 1 & Su-seo & 54 & $\mathrm{~F}$ & Daughter (only) & $\mathrm{F}$ & 83 \\
\hline 2 & Hag-jang & 62 & F & Daughter (first) & $\mathrm{F}$ & 82 \\
\hline 3 & Mi-ae & 50 & $\mathrm{~F}$ & Daughter (first) & $\mathrm{F}$ & 75 \\
\hline 4 & Soon-jong & 65 & $\mathrm{~F}$ & $\mathrm{DIL}^{2}$ (first) & $\mathrm{F}$ & 89 \\
\hline 5 & Mi-joo & 47 & $\mathrm{~F}$ & DIL (youngest) & $\mathrm{F}$ & 89 \\
\hline 6 & Mo-yeon & 58 & F & Daughter (youngest) & $\mathrm{F}$ & 102 \\
\hline 7 & Young-mi & 55 & $\mathrm{~F}$ & DIL (youngest) & $\mathrm{F}$ & 89 \\
\hline 8 & Seong-nye & 52 & $\mathrm{~F}$ & DIL (first) & $\mathrm{F}$ & 83 \\
\hline 9 & Bau-nam ${ }^{3}$ & 57 & M & $\begin{array}{l}\text { Son (first) (husband of } \\
\text { Bau-nyo) }\end{array}$ & $\mathrm{F}$ & 80 \\
\hline 10 & Bau-nyo $^{3}$ & 51 & $\mathrm{~F}$ & DIL (first) & $\mathrm{F}$ & 80 \\
\hline 11 & Su-won & 38 & $\mathrm{~F}$ & DIL (first) & $\mathrm{F}$ & 84 \\
\hline 12 & Na-mi & 62 & F & Wife & M & 65 \\
\hline 13 & $\mathrm{Su}-\mathrm{ji}$ & 55 & F & DIL (first) & $\mathrm{F}$ & 81 \\
\hline 14 & A-joo & 42 & $\mathrm{~F}$ & DIL (youngest) & $\mathrm{F}$ & 83 \\
\hline 15 & Jung-ok & 55 & $\mathrm{~F}$ & Daughter (youngest) & $\mathrm{F}$ & 87 \\
\hline 16 & Yun-kyung & 57 & $\mathrm{~F}$ & DIL (first) & $\mathrm{F}$ & 80 \\
\hline 17 & Hyo-soon & 57 & $\mathrm{~F}$ & DIL (first) & M & 93 \\
\hline 18 & Jong-mal & 55 & $\mathrm{~F}$ & Daughter (youngest) & $\mathrm{F}$ & 85 \\
\hline
\end{tabular}

Notes.

\footnotetext{
${ }^{1}$ Names are all pseudonyms.
} 
${ }^{2}$ DIL means daughter-in-law

${ }^{3}$ Bau-nam and Bau-nyo were a married couple who cared for the same care recipient (Bau-nam's mother).

\subsection{Positive Aspects of Caregiving}

Ten positive aspects [PAs] or benefits of caregiving as experienced by the Korean family caregivers were identified. These ten PAs were categorized again into three emergent themes: relational PAs, personal PAs, and spiritual PAs.

\subsubsection{Relational PAs}

The most common PAs that Korean family caregivers described about their home-based elder care were relational in nature. These PAs were connected with an improvement in the relationship between caregiver and care recipient or between caregiver and other family members, or between care recipient and other family members in the immediate or extended family unit. The relational PAs included positive educational influence on the caregiver's children, strengthened family solidarity or harmony, and simply being with the care recipient.

Positive educational influence on CG's children. The first PA was a positive educational influence on caregiver's children or other siblings. Fifteen family caregivers indicated that caring for older parents provided a living example for their children, who lived together and observed the parents' caregiving, showing the importance of respecting older adults, caring for vulnerable people around them, or being a more selfless person. For example, Young-mi, who has been caring for her mother-in-law while living together with her two children for 26 years, described that her first PA was that her children learned to respect older people.

[Family caregiving is] Good for children. They learn that they should not live a selfish life and should take care of the vulnerable people unconsciously. Even though I do not tell them specifically to behave this way or that way, they learn about what caring is. They learn that they should respect the elderly who are weak. That they are just persons to be respected.

Strengthened family solidarity. Eleven family caregivers described how their family relationship has become closer or tighter as they cared for frail old parents or a husband at home. This study found two different levels of family solidarity: parent-centered family relationships and caregiver-centered family relationships. First, at the level of the parent-centered family relationship, caregiving for the parent at home provided many opportunities for family union for other siblings, because they often visited the older parent who was the center of family solidarity after adult children got married.

Second, at the level of the caregiver-centered relationship, a caregiver's work contributed to a positive family relationship because caregiver's spouse or children were pleased with the fact that they could live together with older parent or grandparent. Young-mi talked about how her caregiving made her husband happy and contributed positively to her relationship with her husband: "Psychologically, my husband feels so happy about living together with his mother, and it's likely that it [his happiness] is transferring to me."

In particular, three participants remarked that it was a positive aspect of their caregiving that the relationship between care recipient and the caregiver's children (usually a grandparental relationship) became very close and intimate. They said that this close relationship with grandparents, based on the grandparents' special love for their grandchildren, was not only beneficial for their children but also contributed to a stronger family unity. Su-ji shared her experience as follow:

Yes, my children. My children became adults now. One is 32 years old, the other is 27 . The oldest is a daughter and the younger is a son. They are very dependent on grand mom. And as they have been living together with grand mom, they are very intimate. That's a good aspect. When they were alone at home, grand mom and grandpa were with them and cared them, and they also took care of [my] mother and father. So it was good for both. I didn't have to worry about them [even when I was out of the home]. I didn't have to always care for them. Other grandchildren are no use [to them]. Only my children they love.

Being present with the care recipient. For some family caregivers, being with older adults while caring for them was described as a PA of their caregiving. Four out of 18 family caregivers mentioned that they appreciated the fact that their parents were still able to be with them, even though they were old and weak so that they needed to be cared for. For example, Mi-ae, who cared for her mother with depression for 13 years, said, "Nonetheless, [my] mom is with me like this. As Mom has been with us, it's a help and strength for us." Yun-kyung also expressed how she felt happy about her family-based caregiving for her mother-in-law. "The happy moment I had [regarding my care for my mother-in-law] was that [I saw] home was not empty but always had the lights on when I came home, and family was there. Mother-in-law is alive." But this PA is mainly based on the previous intimate parent/child relationship between caregiver and care recipient. Three of them were daughters of care recipients, while only one was a daughter-in-law. 


\subsubsection{Personal PAs}

Personal PAs refer to the positive aspects that the family caregivers experienced or received at the personal level physically or emotionally - from their caregiving. Accordingly, these are related with the caregivers' own growth or gains. Personal PAs identified in this study included social support or recognition, appreciation from the care recipient, and a sense of mastery or self-esteem.

Social support or recognition. Ten out of 18 participants reported the social support or recognition they received in relation to their caregiving as an important PA. The family caregivers caring for frail older adults at home were often appreciated for their sacrificial efforts by neighbors, relatives, friends, church congregations, public social service agencies, or government. Specifically, some received emotional support such as verbal appreciation or encouragement, but others also received some type of financial or other physical supports from their extended family or church congregations. Two of them received prestigious awards for their exemplary elder caregiving as social recognition.

Bau-nyo and Hyo-soon were each awarded a medal by the Korean government in recognition of their selfless elder caregiving. In particular, Bau-nyo also received the Samsung Hyo-Haeng (literally, "acts of filial piety") Award, which is one of the most honorable awards in South Korea given to the individuals who are selected through a rigorous process for their dedication to their families by serving older adults. Award winners are recognized and encouraged nationally, and their stories of elder caregiving are spread as models to inspire other people. Hyo-soon shared her story about how she felt when she received the award.

Although I received the award, I didn't have the thought of wanting to receive the award in mind... and my circumstances were such. They said, "No one lives like this now. There's no one in Seoul that lives like this." They said it's extremely rare to see people who have lived [with older parents] under one roof for 32 years.... When I was told that I would receive the award, I said I would decline. I didn't do anything [to deserve that award], and this is the living that I was allotted and received, so I said, "How can I make a big deal out of this?"... [But my boss told me] "Time goes by, and it's what someone else sees, not what you yourself see." So, I finally accepted the award, and though I still can't figure out if I really deserved the award or not, it still felt great.

Appreciation from care recipient. Sometimes the family caregivers of older adults received recognition or appreciation not only from relatives, friends, and neighbors but also from the care recipients they cared for. Four participants stated that the appreciation for their caregiving efforts directly expressed by the care recipients was a rewarding PA they experienced. This PA included the care recipient's special concern and kind words for caregiver, compliments for caregiving efforts in front of relatives or neighbors, and/or financial support as an expression of thankfulness. For example, A-joo, who cared for her mother-in-law for 15 years at home, stated:

I bought her something but she gave me back the money, saying "It's not like you have money." One day, when she said she was going on an excursion, I bought her a piece of clothing... She really loved the color. She was satisfied with it, but she reimbursed me the money. "How much was it?" she asked. I reduced the price. She reimbursed me the money, saying, "It's not like you have money," but she went outside bragging to others that her daughter-in-law bought it for her. After she bragged, other grandmothers caused a ruckus praising her, saying the young daughter-in-law has an eye for fashion.

Increased sense of mastery or self-esteem. Four participants also talked about their increased sense of mastery or improved self-esteem as a PA of the long duration of their elder caregiving. Three participants (Young-mi, Su-won, and $\mathrm{Na}-\mathrm{mi}$ ) reported that they felt proud of their caregiving because they believed that their efforts played an important role in sustaining their family. "I feel proud of myself [about caregiving]. Well done!" said Na-mi. "Many times I would think that I'm living a good life," said Young-mi.

Another participant, Hyo-soon, stated that she became able to understand aged people' behaviors and thoughts more quickly through her caregiving experience. The knowledge and skills developed through her own elder caregiving helped Hyo-soon a lot when she provided voluntary service to older adults in need in the community.

Even if you put a hundred older adults in front of me... I understand their mentality. I know what that older adult wants right now. I can figure out their minds faster.... But someone who hasn't lived with an older adult can't do that.... For us, we can detect it with our eyes, what that older adult wants and how. I am a hundred percent confident when it comes to an older adult's mentality.

Assisting with household chores. Sometimes family caregivers also received some physical or financial assistance with house chores from care recipients they cared for, when they were in serious condition. Five participants mentioned that despite their frailty their care recipients occasionally gave assistance to them with house chores such as dishwashing, ironing, childcare, cooking, or financial support for food. Care recipients' assistance with house chores was helpful for 
caregivers, but it often played an important role for care recipients by thinking that they were contributing something meaningful for their caregivers or families. Seong-nye, who cared for her mother-in-law for eight years, remarked,

She always likes to do the ironing. Her son always wears dress shirts. After I do laundry, ironing is her joy. Pressing. It's hot, but it's her joy to iron dress shirts.

In case of A-joo, her mother-in-law provided financial support for some part of living costs (e.g., food materials). A-joo stated that although she did not need financial support from her mother-in-law, she received it because her mother-in-law felt good about it.

Mother-in-law is responsible for the expenses for preparing for major food. Well, gimchi or rice, of course, I can buy them [with my money]. But she bears the whole expenses for that food saying "I want to do this as long as I can afford it." That's a good aspect... She is responsible for all the big expenses for food financially.

\subsubsection{Spiritual PAs}

The current study found that a third theme in the PAs that Korean family caregivers of older adults experienced was explicitly related to spirituality. These are not necessarily mutually exclusive with the other kinds of PAs. However, these explicit spiritual PAs are differentiated from other PAs described earlier in that they are not about specific social gains but related to something higher such as transcendence of self, experience of God, spiritual maturity, forgiveness or healing, and expanded empathy with other people. All of the caregivers of this study were affiliated with a traditional religion such as Christianity or Buddhism. As a result, some spiritual PAs were directly connected with the specific religion the caregivers were involved in, but other PAs were not religion specific.

Spiritual growth or maturity. Six participants described that they experienced spiritual growth or maturity as a result of elder caregiving. They interpreted their caregiving experience as a good opportunity to train themselves for spiritual growth or maturity, in order to meet God, and to feel God's heart for other people in the same situation as themselves.

Four participants (Su-seo, Mi-ju, Mo-yeon, and Su-won) depicted their elder caregiving experience as a course of special training that God purposively designed for their spiritual growth and maturity. For example, Mo-yeon mentioned that she considered caring for her mother, who was 102 years old, what God gave her as a ministry for her own PA, and that she became mature through the trial time of caregiving she had to go through.

Even if I didn't have faith, I probably would have taken care of her because of my personality, but I would have sought rewards or complained... or taken out my irritation on my sisters; I guess I would've done like that. Instead I don't think there's any of that. Because, like I said, just like the Lord has given me the job of taking care of my mother, certain children are entrusted with taking care of their parents. That's a job that was given to me. Further, it may be that the Lord has given me this job for my benefit.... Even though I couldn't take care of her well, I got trained through this

Two participants (Su-seo, Young-mi) stated that the hardship of the caregiving experience provided them a precious opportunity of meeting God. The expression of "meeting God" was used by them as a religious expression meaning a spiritual experience of change or maturity. Su-seo said:

This suffering was too hard for me, but it made me seek to meet God earnestly, earnestly. [Because I often had to ask God] "God, it's too hard for me. What is this? What can I do for my mom when she behaves like this?"

Emotional healing. Two participants reported that they had an experience of emotional healing during the process of their caregiving to older adults while living together. They said that they kept some regrets or emotional hurts that they had received from the care recipients (their parents) in the past. But the home-based caregiving provided an opportunity for the caregivers to have an increased understanding of their parents and their lives, and this helped them heal their past emotional hurts and rebuild a good relationship with a care recipient.

Jong-mal, for example, who brought her mother into her home out of a long-term care facility, had some resentments against her mother because her mother did not care for her when she gave birth. (In Korea, because women, who do not get proper care after giving birth, could suffer from diseases such as arthritis, post-natal women traditionally were not allowed to go outdoors or do difficult chores at home. Culturally their mothers have been expected to provide post-childbirth care even after their daughters got married.) As she began to provide care for her mother living now at home, those regrets and past emotional wounds hidden in her mind revealed themselves and made her caregiving difficult. But she said that her caregiving time was a time of healing her hurt emotions and restoring a good relationship with her mother.

It was hard in the beginning, in my thoughts. In living together, I didn't know in my daily life that I had complaints toward mother. In living apart. They come out when we came into conflict [while living together].... For example, I suddenly had the thought of not being protected [by her] when I gave birth, when I 
had my first child.... So at first, because of those things, I didn't want to see her, since the bad thoughts continued to come instead of the good ones. But how that changed over time is that when the bad thoughts come out can be times of healing for me; they may be times for my relationship with my mother to recover. For my mother's situation at that time, even though situations differ for everyone, what she did was her best; my thoughts changed like that.

Expanded empathy with other's sufferings. One participant, Su-seo, said that the act of caregiving helped develop an expanded perspective that she could easily feel and empathize with other people's sufferings with "God's heart." Su-seo remarked:

This is how I realized that my spirituality has deepened... No matter whom I meet or what I hear, I am reminded of how our Father, God, must be feeling, how exactly our Father God's mind must be. It's becoming like that. That's how it is these days. Like that. Ah, that's how our Father God must be feeling. I feel that from the bottom of my heart. I think that has become different. From before... I am trying to be more sympathetic. "Yes, it's hard, isn't it? It's hard to take care of older adults like grandmothers." I sympathize with them enough.

\section{Discussion}

The purpose of this study was to gain a deeper understanding of the positive aspects of home-based caregiving experience of Korean family caregivers who cared for elderly family members. Despite the stressful nature of family caregiving, amazingly, all the Korean family caregivers in this study reported that they also had a variety of positive outcomes from their home-based elder caregiving experience. In general, the findings of this study confirmed previous studies on family caregiving of older adults in the Western context in reporting on the dual nature of family caregiving for older adults (e.g., Carbonneau, Caron, \& Desrosiers, 2010; Hilgeman et al., 2007; Kramer, 1997; Roff et al., 2004; Sanders, 2005). It has been observed that such caregiving involves both stresses and rewards, burdens and satisfactions. Although the cultural style is different in East Asian contexts, this complicated quality has been often reported.

One of the most meaningful findings of this study concerns the benefits or positive aspects of the home-based Korean family caregiving experience with older adults. As noted earlier, there was a dearth of knowledge about the positive aspects of Korean family caregiving with older adults. In this exploratory study, various positive aspects of Korean family caregivers' caregiving experience were brought to light, which had been ignored by earlier problem-focused approaches to home-based elder caregiving in Korea. Elder caregiving at home by family members is undoubtedly laden with many burdens. However, it also presents an opportunity for growth and change of caregivers as evidenced by the findings of this study.

Several major positive aspects of the elder caregiving experience were identified, which were categorized into three groups: personal PAs, relational PAs, and spiritual PAs. Many of the Pas were congruent with those found in previous studies on some American ethnic groups' or other country's caregiving experience (e.g., Hodge \& Sun, 2012; Netto, Jeny, \& Phillip, 2009; Sanders, 2005).

Personal PAs comprised support, recognition, or praise for the caregiver and caregiving efforts from neighbors or community, appreciation from the care recipient, an increased sense of mastery or self-esteem, and an assisting with household chores by care recipients. The most mentioned PAs in this study, however, were 'relational' in nature. These included positive educational influence on a caregiver's children, strengthened family solidarity, and being with a care recipient. These relational PAs also revealed the cultural context of home-based elder caregiving in Korea. As mentioned, the care recipients of this study were older adults co-residing with their family caregiver and/or caregiver's family. That is, in case of parental care, the caregiving happened in the setting of a multi-generational family structure, in which relationships among family members are considered important. As a result, participants were able to identify several merits related to their relationships with children, siblings, and care recipients, though they were often simultaneously struggling with relational challenges.

Another area of home-based elder family caregiving PAs was the spiritual PA group, which were shaped by Korean forms of belief in Christianity, Buddhism, and Confucianism. As a result of their caregiving, some participants experienced spiritual gains such as spiritual growth and maturity, emotional healing experiences, and expanded empathy with others. Spiritual growth and maturity could be also considered as belonging into the personal PA group because it is also about a person's personal growth, but it was categorized as a spiritual PA, as it is deeply related to the caregiver's religious or spiritual perceptions of caregiving. Such spiritual PAs have been found in other studies. For example, Netto, Jenny, and Phillip (2009) also reported 'higher-level' gains experienced by family caregivers of persons with dementia in Singapore including positive change in philosophy, spiritual growth and altruism. Spiritual PAs of this study are congruent with their findings. 
The spiritual aspects of caregiving benefits reveal that home-based family caregiving of older adults can be also a spiritual experience for some family caregivers through which they can grow and change, becoming a more mature person with a transcendent perspective on the people around them. As Pargament and Mahoney (2005) described that secular aspects of life can be perceived as having spiritual character and significance by the process of "sanctification," some family caregivers of this study began to view their caregiving role as something sacred like God's calling. Through this process of sanctification of family elder caregiving, family caregivers in this study were motivated to invest their time and effort to their caregiving and found more positive spiritual gains from the stressful caregiving experience. In this sense, the participants' perception of the PAs and challenges implicates the influence of their cultural values and spirituality on their caregiving. Family caregiving is a human experience linking whole areas of a person.

Findings of this study highlight the importance of holistic approach to home-based family caregiving of older adults by including the positive aspects. This implies that the interventions utilizing the positive aspects of the elder family caregiving experience may be more effective in enhancing the wellbeing of the family caregivers who experience caregiving as positive one. Despite differences of cultural context, the findings of this study have implications in the design and delivery of services for intervention with diverse ethnic families caring for older adults with frailty. However, it is also important that the presence of PAs should not be exploited as a reason to rationalize lack of access to services from which family caregivers could benefit.

There are limitations of this study. First, given the qualitative nature of the current study and the limits in sampling procedures, it is not intended to generalize the findings of this study to Korean family caregiving population in general or other wider populations in a statistical sense, though it offers some insights into the research that can be built upon in further studies. Another limitation has to do with the trustworthiness of results. Various measures were taken to protect the rigor of this study including credibility, dependability, confirmability and transferability. Different types of informal caregivers were recruited to capture different views and experiences of the participating caregivers. A rigorous data collection and comprehensive data analysis was performed to support data saturation and robust reports of data by using multiple reviewers to ensure that participants' viewpoints were adequately interpreted.

In conclusion, this study identified several positive aspects of the elder caregiving experienced by Korean family caregivers. This includes personal PAs, relational PAs, and spiritual PAs. Korean home-based family caregivers of older adults identified them as important in maintaining a positive caregiving experience. Despite the need for consideration of the cultural context, these findings can inform future studies that aim to enhance the experiences of family caregivers of older adults, which leads to the quality of life of the older adults they care for.

\section{References}

Berg-Weger, M., Rubio, D. M., \& Tebb, S. S. (2001). Strengths-based practice with family caregivers of the chronically ill: Qualitative insights. Families in Society, 82(3), 263-272. https://doi.org/10.1606/1044-3894.191

Carbonneau, H., Caron, C., \& Desrosiers, J. (2010). Development of a conceptual framework of positive aspects of caregiving in dementia. Dementia, 9(3), 327-353. https://doi.org/10.1177/1471301210375316

Dilworth-Anderson, P., Goodwin, P. Y., William, S. W., Williams, R. B., \& Siegler, I. C. (2005). Effect of race on cultural justifications for caregiving. The Journals of Gerontology Series B Psychological Sciences and Social Sciences, 60, 257-262. https://doi.org/10.1093/geronb/60.5.S257

Etters, L., Goodall, D., \& Harrison, B. E. (2008). Caregiver burden among dementia patient caregivers: a review of the literature. Journal of the American Academy of Nurse Practitioners, 20(8), 423-428. https://doi.org/10.1111/j.1745-7599.2008.00342.x

Folkman, S. (1997). Positive psychological states and coping with severe stress. Social Science and Medicine, 45, 1207-1221. https://doi.org/10.1016/S0277-9536(97)00040-3

Hilgeman, M. M., Allen, R. S., DeCoster, J., \& Burgio, L. D. (2007). Positive aspects of caregiving as a moderator of treatment outcome over 12 months. Psychology and Aging, 22, 361-371. https://doi.org/10.1037/0882-7974.22.2.361

Hodge, D. R., \& Sun, F. (2012). Positive feelings of caregiving among Latino Alzheimer's family caregivers: Understanding the role of spirituality. Aging \& Mental Health, 16(6), 689-698. https://doi.org/10.1080/13607863.2012.678481

Hunt, C. K. (2003). Concepts in caregiver research. Journal of Nursing Scholarship, 35(1), 27-32. https://doi.org/10.1111/j.1547-5069.2003.00027.x

Korea National Statistical Office. (2019). 2019 Aged Population Statistics. Seoul: Republic of Korea. Retrieved from http://kostat.go.kr/portal/korea/kor_nw/1/1/index.board?bmode=read\&aSeq=377701 
Kramer, B. J. (1997). Gain in the caregiving experience: Where are we? What next? The Gerontologist, 37, 218-232. https://doi.org/10.1093/geront/37.2.218

Lee, H. J., Seo, J. M, \& Ahn, S. H. (2003). The role of social support in the relationship between stress and depression among family caregivers of older adults with dementia. Journal of Korean Academy of Nursing, 33(6), 713-721. https://doi.org/10.4040/jkan.2003.33.6.713

Lee, Y. W., Lim, J. Y., Kim, J. Y., Cho, H. I., \& Ko, G. J. (2011). A prediction model for caregiver burden and life satisfaction: Caring for a patient with dementia. Journal of Korean Gerontological Nursing, 13(3), 204-214. https://doi.org/10.17079/jkgn.2018.20.3.204

Lincoln, Y., \& Guba, E. (1985). Naturalistic Inquiry. Thousand Oaks, CA: Sage Publications. https://doi.org/10.1016/0147-1767(85)90062-8

Merriam, S. (1998). Qualitative research and case study applications in education. San Francisco: Jossey-Bass.

Netto, N. R., Jenny, G. Y. N., \& Philip, Y. L. K. (2009). Growing and gaining through caring for a loved one with dementia. Dementia, 8(2), 245-261. https://doi.org/10.1177/1471301209103269

Pargarment, K. I., \& Mahoney, A. (2005). Sacred matters: Sanctification as a vital topic for the psychology of religion. International Journal for the Psychology of Religion, 15(3), 179-198. https://doi.org/10.1207/s15327582ijpr1503_1

Pinquart, M., \& Sörensen, S. (2005). Ethnic differences in stressors, resources, and psychological outcomes of family caregiving: A meta-analysis. The Gerontologist, 45(1), 90-106. https://doi.org/10.1093/geront/45.1.90

Rapp, S. R., \& Chao, D. (2000) Appraisals of strain and of gain: Effects on psychological wellbeing of caregivers of dementia patients. Aging \& Mental Health, 4, 142-147. https://doi.org/10.1080/13607860050008664

Robertson, S. M., Zarit, S. H., Duncan, L. G., Rovine, M. J., \& Femia, E. E. (2007). Family caregivers Patterns of positive and negative affect. Family Relations, 56, 12-23. https://doi.org/10.1111/j.1741-3729.2007.00436.x

Roff, L. L., Burgio, L. D., Gitlin, L., Nichols, L., Chaplin, W., \& Hardin, J. M. (2004). Positive aspects of Alzheimer's caregiving: The role of race. Journal of Gerontology B Psychological Sciences and Social Sciences, 59, 185-190. https://doi.org/10.1093/geronb/59.4.P185

Saleebey, D. (1996). The strengths perspective in social work practice: Extensions and cautions. Social Work, 41, 295-305.

Saleebey, D. (Ed.). (2013). The Strengths Perspective in social work practice (6th ed.). Boston: Pearson.

Sanders, S. (2005). Is the glass half empty or half full? Reflections on strain and gain in caregivers of individuals with Alzheimer's disease. Social Work in Health Care, 40(3), 57-73. https://doi.org/10.1300/J010v40n03_04

Schulz, R., Belle, S. H., Czaja, S. J., McGinnis, K. A., Stevens, A., \& Zhang, S. (2004). Long-term care placement of dementia patients and caregiver health and well-being. JAMA, 292(8), 961-967. https://doi.org/10.1001/jama.292.8.961

Song, M. Y., \& Choe, G. G. (2007). The decision factor on primary caregiver's burden for senile dementia elderly. Journal of Welfare for the Aged, 37, 131-160.

Thompson, L. (2004, March). Long-term care: Support for family caregivers. Washington, DC: Georgetown University Long-Term Care Financing Project. Retrieved from http://tc.georgetown.edu/pdfs/caregivers.pdf

Toseland, R., Smith, G., \& McCallion, P. (2001). Family caregivers of the frail elderly. In A. Gutterman (Ed.), Handbook of social work practice with vulnerable and resilient populations (pp. 548-581). New York: Columbia University Press.

\section{Copyrights}

Copyright for this article is retained by the author(s), with first publication rights granted to the journal.

This is an open-access article distributed under the terms and conditions of the Creative Commons Attribution license which permits unrestricted use, distribution, and reproduction in any medium, provided the original work is properly cited. 